\title{
Embedded Tasks as Stimulus to Human Information Behaviour
}

\author{
${ }^{1}$ Ibrahim Salihu Yusuf, ${ }^{2}$ Halilu Sani Shuaibu and ${ }^{3}$ Hamza Ukashatu Musa \\ KASHIM IBRAHIM LIBRARY, Ahmadu Bello University, Zaria
}

\begin{abstract}
The paper is captured within the dynamics of Human Information Behaviour in an Academic Library setting of Ahmadu Bello University. It indicated how instinct of information needs are triggered by tasks individuals intend to perform or accomplish. Survey method was used to carry out the investigation. Questionnaire was used to generate data on likely tasks. Dissertation; Thesis and Project received 23(46\%) response as tasks that bring people to the Library followed by administrative and independent study with $12(24 \%)$ and $10(20 \%)$ as another tasks that stimulate people to look for information in the library. The paper recommended that Library and Information Centers should adopt User-Task-Approach to information service delivery to ensure optimum and efficient utilization of fund and allowed them to adjust to dwindling fund allocations. The importance of up-dating existing information collections is relevant to providing quality service. Users are satisfied when they check back again. Satisfaction is guaranteed by maintaining current information collections.
\end{abstract}

Key ward: Human; Information Behavior: information need

\section{Introduction}

Human Information Behaviour is the sum what culture of human in a bid to secure access and obtain piece of information. The behaviour is marked with myriad activities which range from information foraging, information seeking, retrieval and use. According to T.D Wilson (2000) is the totality of human behaviour in relation to sources and channels of information, including both active and passive information seeking and information use. Thus Human Information Behaviour is a conglomeration of distinct patterns of display employed by individual when the need for information is envisaged. There are a number of identified factors that inform individual on the need for information. One of them is task; simply a piece of work one intends to or a job or any other assignment that informs an individual that he needs information.

H N Prasad (2009) was of the opinion that the Information needs of users are of central concern to providers of information service. The ultimate aim of any information retrieval system is to supply and deliver the information which can precisely match the information request or requirements. It is beyond doubt that the success of information service is more likely to be achieved by adjusting the services to meet the specific needs of an individual rather than trying to match the output of the information systems. In order to provide information that meet the needs of individual it is paramount to look into the tasks that triggers information need within the dynamics of information behaviour. The setting for this test is an Academic Library (Kashim Ibrahim Library) situated in Ahmadu Bello University Zaria-Nigeria.

\section{Statement of the Problem}

The information handling activities are to be based entirely on the needs of the users. The user category has different needs for information depending upon functions, responsibilities and duties. According to $\mathrm{H} \mathrm{N}$ Prasad (2009) the user groups include government officials, legislators, parliamentarians, industrial entrepreneurs, researchers, lecturers, students, skilled workers in various sectors of production, grass level people and the general public. Information needs varies distinctly among the categories of users. The marching of information needs to sources of information has to be based on the careful assessment of information need. To achieve a thorough assessment of these needs, it is important to understand tasks that form the context for information behaviour because these tasks have direct as well as indirect interactions with people's informationseeking activities and are a primary but under-studied phenomenon (Barbara M. Wildemuth and Anthony Hughes, 2005)

Furthermore, understanding these tasks will enable information service providers to acquire process, organize and disseminate information resources and services that would meet the specific information needs of individuals rather than by the use of system approach to the matter. 


\section{Research Questions}

1. What are the tasks that inform an individual that he needs information?

a. Could it be thesis or dissertation task?

b. Could it be administrative task

c. Could it be study task

d. Recreational task

2. How has embedding task affected individual's information seeking behaviours?

a. With respect to which source to be considered trustworthy

b. With respect to satisfaction with the outcomes of a search.

c. With respect to whether the source yielded positive information needed to accomplish tasks at hand.

\section{Objectives of the study}

1. To understand the types of tasks that inform individuals on the need for information and make them come to the Library.

2. To ascertain the extent at which embedded tasks interfere in the affective reactions of individuals during their information seeking process.

3. To know whether users often get what they want and are satisfied

4. To determine whether sources of information in the Library and information centers often yield the desired result.

\section{Significance of the study}

This study present library and information service professionals with essential dynamics to understanding the granularity that are encapsulated in the provision of information resources and services. The granularity indicated tasks approach to delivering of information services rather than using system approach. The tasks are various activities that stimulate the need for information.

Furthermore, it informs information professionals of users behaviours when they envisage the need for information, and how their affective reactions interfere with tasks they intend to perform when they search for information.

This study is important when designing information retrieval system as a simulation of naturalistic behaviour of how users of an information retrieval system would react in reality when the system is finally mature and ready for use.

\section{Review of Related Literature}

The relevance of information is seen in the outcome of the task the information is put to solve. People undertake an almost infinite variety of information behaviours. In almost all cases, these information behaviours are undertaken within the context of some other purpose, goal, or activity. In other words, the person's information behaviours are situated within the context of larger task or set of tasks. Allen $(1996,1997)$ proposed a person -in- situation approach to our understanding of information needs. As he noted, information needs happen to individuals who are embedded in a range of social situations. Allen considered four sources of influence on an individual's information needs and subsequently on an individual's information seeking behaviour. The four sources of influence include individual influences (i.e. knowledge structures and perception), situational/social influences on the individual's needs, individual influences on a groups needs (Based on the assumption that a group has information needs beyond those of its individual members), and situational/social influences on a group's needs. Allen's model is in line with Dervin's (1999) and Savolainen's (1993) more process- view of information behaviours. They stated that when someone experiences a discontinuity in his or her sense making activities, additional information may be sought to resolve that discontinuity. The discontinuity is bridged by asking questions, forming ideas, obtaining resources, and, finally, developing strategies that allow the effective use of these ideas and resources.

While Allen's and Dervin's work took the same appropriate direction, further investigation is needed to more fully understand how people's experiences of information needs and their information behaviours are embedded within their accomplishment of other tasks. In their information foraging theory, Pirolli and Card (1999) described these as the task environment or embedding task of information seeking. They put forward that the embedding task motivates someone to seek information and that the outcomes of the information-seeking process will be evaluated in relation to their effects on the outcomes of the embedding task. This is true in that when one is planning a vacation, one might want to find out more about sites in the country one intends to travel to. Thus, the embedding task for the particular search is vacation planning. Barbara M. Wildemuth and Anthony Hughes (2005) emphasized that it seem likely that the information-seeking process will be affected by the searcher's emotional responses, personal history of travel, and expectations concerning the preferences of travel 
partners, as well as the match between an information source's content and the searcher's topic. In addition, the outcomes of the search will be evaluated in relation to the outcomes of the vacation planning process.

However, as we gain a better understanding of the types of embedding tasks that provide the context for particular information behaviours, we will be better able to understand the processes of information seeking and use.

\section{Methodology}

Survey methodology involving a closed-ended questionnaire was used to collect written responses from 56 users of kashim Ibrahim Library, Ahmadu Bello University, Zaria.

\section{Data Analysis and Discussion}

The researcher worked with research assistants to administer and retrieved questionnaire. A total of 56 copies of questionnaire were administered to users that came into Kashim Ibrahim Library within the period of two weeks and from $10 \mathrm{am}$ to $2 \mathrm{pm}$.

The data was collected and analyzed using descriptive statistic. Descriptive measures such as frequency distribution. Percentages and means were used to answer the research questions. A total of $50(89.3 \%)$ copies of questionnaire were retrieved and found valid for analysis.

Table1: Distribution of Respondents by Gender

\begin{tabular}{|l|l|l|}
\hline Gender & Frequency & Percentage \\
\hline Male & 29 & 58 \\
Female & 21 & 42 \\
\hline Total & $\mathbf{5 0}$ & $\mathbf{1 0 0 \%}$ \\
\hline
\end{tabular}

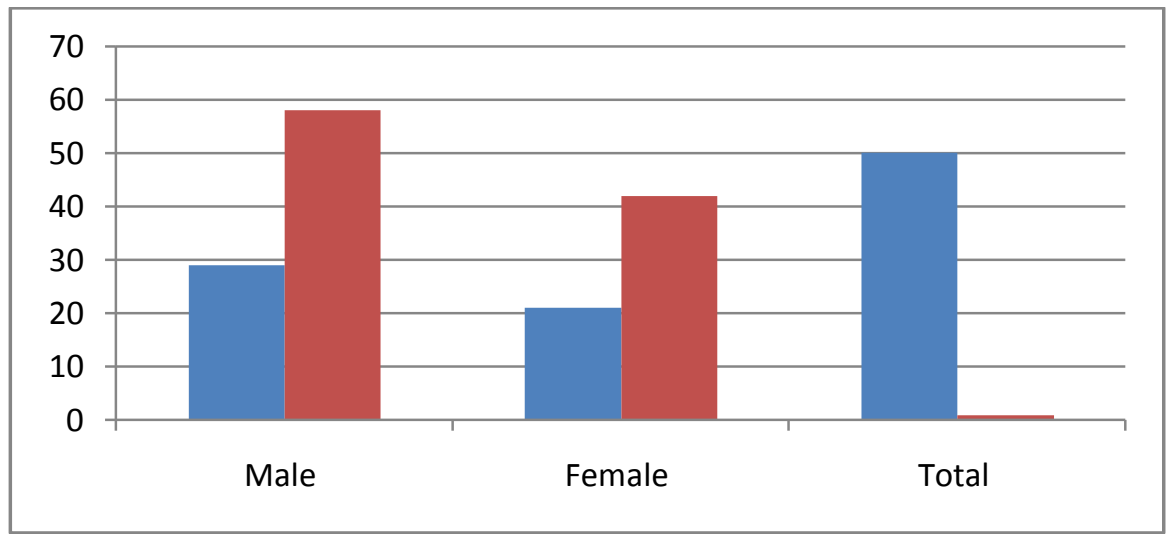

Figure 1

The table above showed that the number of female citizen of Ahmadu Bello University as at when the data was collected was $21(42 \%)$ and male number was $29(58 \%)$. This analysis showed that, within the period questionnaire was administered number of male coming to the library were much.

Table2: Distribution of Respondents by Category

\begin{tabular}{|l|l|l|}
\hline Category & Frequency & Percentage \\
\hline Undergraduate & 15 & 30 \\
Post graduate & 16 & 32 \\
Academic staff & 14 & 28 \\
Non Academic Staff & 5 & 10 \\
\hline Total & $\mathbf{5 0}$ & $\mathbf{1 0 0} \%$ \\
\hline
\end{tabular}




\section{Distribution of Respondents}

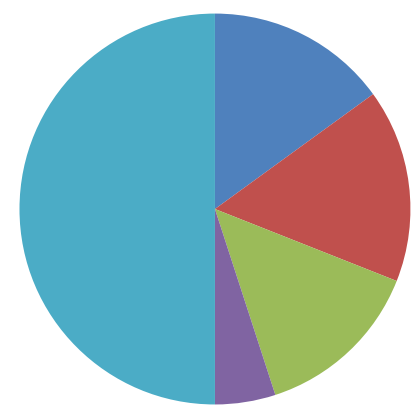

- Undergraduate

- Post graduate

Academic staff

Non Academic Staff

- Total

Figure 2

To ascertain the categories of respondents that visited kashim Ibrahim Library within the period the questionnaire were administered, this table indicated that non Academic staff were the least 1 with 5(10\%), post graduates as well as undergraduates were much with $16(32 \%)$ and $15(30 \%)$ and then followed by Academic staff with $14(28 \%)$. It is obvious from the table that non Academic staff in Ahmadu Bello University had the least task to perform during the time period.

Table 3: Tasks that inform individual on the need for information

\begin{tabular}{|l|l|l|}
\hline Tasks & Frequency & Percentage \\
\hline Dissertation/Thesis/project & 23 & 46 \\
Administrative & 12 & 24 \\
Recreational & 5 & 10 \\
Independent Study & 10 & 20 \\
Others & - & - \\
\hline Total & $\mathbf{5 0}$ & $\mathbf{1 0 0 \%}$ \\
\hline
\end{tabular}

The above table points to the tasks or assignments that inform individuals that they need information to enable them carry out their various tasks. Individuals that needed information on Dissertation/Thesis/Project work amounted to $23(46 \%)$ this indicated that kashim Ibrahim Library is heavily used by final year students and for fulfilling the requirements for the award of degrees. Whereas those that used the library for administrative and independent study tasks were $12(24 \%)$ and $10(20 \%)$ Recreational task had the least with just 5(10\%) this point to fact that recreational activities that gives individuals room to display their generic abilities in art and literature is at its lowest ebb.

Table 4: How has Embedding Tasks affected users information seeking behaviour?

\begin{tabular}{|l|l|l|l|l|}
\hline Affection & Frequency & \multicolumn{2}{l|}{ Percentage } \\
\hline Trustworthy of source & $13(\mathrm{n})$ & $10(\mathrm{y})$ & 59.1 & 35.7 \\
Outcome of the source & 6 & 11 & 27.3 & 39.3 \\
Task accomplishment & 3 & 7 & 13.6 & 25.0 \\
\hline Total & $\mathbf{2 2}$ & $\mathbf{2 8}$ & $\mathbf{1 0 0} \%$ & $\mathbf{1 0 0} \%$ \\
\hline
\end{tabular}

Note: $\mathrm{n}=$ no. $\mathrm{y}=$ yes.

While kulthau's (1991) work examined students' affective reaction to information seeking process, she did not study their affective reactions to the embedding task. This table indicated how individuals ascertain the genuity of source of information; the results of the source when searched and the ability of the yielded results at enabling them accomplish their tasks. 13(59.1\%) of individuals that visited Kashim Ibrahim Library said that they had no problem thinking about questioning the trustworthiness of the information source they consulted while $10(35.7 \%)$ registered their distrust with the information source they used, this was because they didn't get up-to-date information from the source they used for their tasks. However, 6(27.3\%) of users were dissatisfied with the overall performance of the library in solving their task related information need but on the contrary $11(39.3 \%)$ expressed their satisfaction. Suspiciously, only $7(25.0 \%)$ of the individuals said the information they retrieved enhanced their ability to solve their tasks

\section{Summary}

The relevance of understanding various tasks that inform individuals on the need for information has established a paradigm shift from system approach to user task Approach to the processes of information 
acquisition, processing, organization and dissemination. It provides simpler processes to information acquisition and dissemination as opposed to the traditional tedious processes of collection development which does not ensure strategic and efficient utilization of fund to achieve optimum result. Task approach educates Library and information services providers to study and know the various tasks that people undertake in their endeavours to render accurate and timely information services.

\section{Recommendation}

From the presentation and analysis of data the following general recommendations were made:

1. Library and Information Centers should adopt User-Task-Approach to information service delivery as it will ensure optimum and efficient utilization of fund and allowed them to adjust to dwindling fund allocation from source.

2. The importance of up-dating existing information collections is relevant to providing quality service. Users are satisfied when they check back again. The satisfaction is guaranteed by maintaining current information collections.

3. Source of information has affective impact on user's ability to use it to accomplish his task. Good source present users with comfort and convenience of use. An ideal source should indicate its bibliographic details.

4. There is the need for Library and information centers to maintain user satisfaction record. It would help evaluate the quality of service rendered. In terms of whether users were able to accomplish their task and the degree of accomplishment e.t.c.

\section{References}

[1]. Allen, B.(1997). Information needs: A person-in-situation approach. In vakkari, P., Savolainen, R., \& Dervin, B. (Eds.), Information seeking in context: Proceedings of an international conference on research in information needs, seeking and use in different contexts.(pp.111-122). London: Tylor Graham.

[2]. Allen, B.L. (1996). Information tasks: Toward a user-centered approach to information systems. San Diego: Academic Press.

[3]. Barbara M. Wildemuth and Anthony Hughes (2005) perspectives on the Tasks in which Information Behaviours Are Embedded: The Theories of Information Behaviour. Information Today, Inc: Medford, New Jersey. Pp. 275.

[4]. Dervin, B. (1999). On studying information seeking methodology: The implications of connecting metatheory to method. Information Processing \& Management.

[5]. H N Prasad (2009) information need and users: ATICULO. Vol. 8 FORINFO ABRIL-JUNIO, 2009.

[6]. Kuhlthau, C.C. (1991) Inside the search Process: Information Seeking form the user's perspective. Journal of the American Society for Information Science, Vol. 42, 361-371.

[7]. Pirolli, P., \& Card, S. (1999). Information foraging. Psychological Review.

[8]. Savolainen, R. (1993). The Sense-Making theory: Reviewing the interests of a user-centered approach to information seeking and use. Information Processing \& Management.

[9]. T.D Wilson (2000) Human Information Behaviour: Special issue on information science research. Vol. 3. 